\title{
INDUSTRIAL REVOLUTION FOR BETTER LIVING
}

\section{J. MANOJ KUMAR}

Assistant Professor, Department of Mechanical Engineering, S R Engineering College, Warangal, Telangana, India

\section{ABSTRACT}

The science and technology brought many changes in human lives. The science and technology made the humans to be civilized. The earlier industrial revolutions 1, 2, 3 made human lives comfortable with goods and services. Even though there are some problems faced by humans due to industrial revolutions, it's agreed that they changed the human way of living. The developments of science and technology are rapidly growing day by day. Every day there are numerous new innovations of goods, technology etc. These new innovations are making human life more comfortable and luxurious with least human effort. In this investigation, I am going to explain the revolutionized methods of industries. The physical efforts made by human beings in daily life are gradually decreased to noticeable levels. Now human are making less physical efforts than the previous. In case the new industrial revolution may come to reality, how could it be? Every human being should have a literacy about the industrial revolution 4 i.e. IR4. The humans, the governments, the society should be ready to accept the 4th IR. Humans should be able to know its effects on civil societies etc. every human should be able to use the new materials, new products, new services. The innocence about IR 4 can cause lot of damage to individual people in leading their daily life. Humans should understand machines and should be able to contact and communicate with them. The humans should respect the nature to be protected from natural calamities. In this paper an attempt is made to understand the IR 4.

KEYWORDS: Industrial Revolution, Science, Technology, Smart Materials, Computer and Information Technology, Clean and Green Technologies

Received: May 12, 2020; Accepted: Jun 02, 2020; Published: Jul 17, 2020; Paper Id.: IJMPERDJUN2020365

\section{INTRODUCTION}

According to the Cambridge Dictionary (2017), the term industrial revolution is initially defined as: "the period of time during which work began to be done more by machines in factories than by hand at home". The advances in science and technology have continuously supported the development of industrialization all around the world, and have helped to bring more specific and explicit meanings to this term over the years (Belvedere et al., 2013). Nowadays, even though there is still no universal agreement on what constitutes an industrial revolution (Maynard, 2015), four general phases have been identified from the perspective of the technological revolution (National Academy of Science and Engineering, 2013).The James watt steam engine made the growth in industrial production, this invention made the first IR in the end of $18^{\text {th }}$ century. The electrical powered mass production technologies at the beginning of 20th century made the second IR. The mass production of materials, machines, goods further improved the production performance with integration of machines with electronics and computer information technology. This made the third IR. In recent years more fields of computer science, Information technology and electronics engineering are coming into picture. The fields like embedded systems, artificial intelligence, robotics, cloud computing, internet of things IoT and cyber physical systems are emerging in the latest times. The integration of these fields to improve productivity, performance and business is called the IR4. The IR 4 is aimed to link the Men - Machine with intelligence. 


\section{LITERATURE REVIEW}

Klaus Schwab et. al., explained the possible methods to have $3 \mathrm{D}$ printing of cars, $3 \mathrm{D}$ printed liver transplantation, and the machines reading human minds. The fourth industrial revolution has unlimited scope, can be used for mobile networking, nanotechnology, brain research, material science, computing etc.

Megan Crouseet. al., noted that the IR 4 can be used for robotic service workers, Nano technology, renewable energy, brain and artificial intelligence and combinations of many more fields. The technology used in IR4 is very fast in working. Megan Crouse quoted that the big fish eats small fish is old saying, the new saying is fast fish eats slow fish. The companies which do not follow this saying will be closed.

Heather Stewartet. al., stated that the present robots are used for assembling the machine components and similar works. The tomorrow's robots can think and judge the things as humans. Things will have an unlimited impact on mass production. Such development of robots will be risk to present workers, they may lose jobs from $35 \%$ to $47 \%$.

Klaus Schwab et.al., said that, we should understand and shape the new technology in other words it transforms the humankind. The fundamental change takes place in the way we live, work and relates to one another. Human kind will experience the things which never happened earlier. IR 4 includes many more, like artificial intelligence, internet $\mathrm{f}$ things ioT, autonomous vehicles, bio technology, energy storage, quantum computing. New ways of using technology is to change our behavior and systems of production.

JaapBloemet.al., Noted that the silent revolution is taking place, the internet, sensors and embedded systems etc. opened opportunities for new products which involves the combination of mental and physical things. "Pervasive Computing" is a new field of integration of Information Technology (IT) and Operational Technology (OT). No wonder if the change takes how we brush our teeth by this technology. The costs of products will come down rapidly with human machine interaction. Digitalization of things will happen in entire systems.

The industrial revolutions 4 entered the new phase of science and technology and also have a great impact on computer science and information technology. İlker Güven Yilmaz et al noted that the companies will take the advantage of new facilities available with technology and make profits. The new features in existing social media services will be included and the existing features will be updated with new things. Social media is considered for meaningful information transfer resource.

There will be shift in the way we use technology, communication systems, data and its analysis etc. the Governments and people has a great role to harness the power of IR4. IR 4 improves the sustainability, growth in the industry and improves the economic prosperity. Every sector of human society can use IR 4.

IR4 affects every facet of manufacturing units, firms, companies, business etc. it's involved in super computing, geo engineering, space technologies and many more. It makes its impact on Economics, Society and politics. It assures a change in the future jobs, and the lifestyle preferences. This also increases the living ages of human beings, the average life will be increased with increase in medical and living conditions. The governments should play their role in educating the people about IR4.

Long term solutions to the development perspectives for an African population have to be considered to decrease the income level gaps between Africa and the rest of world. Agriculture is more effective in reducing the people's poverty 
whereas the industrial development can rapidly increase the economic growth. IR 4 can guaranty the productivity and growth.

The fourth industrial revolution has an integrated relationship between technology and business. The future business creates the digital assets embedded with digital business. Uber is an example of business linked with technology, brand made changes in the existing business. The technologies like cloud computing, big data and IOT and their combinations can give more personalized products and services.

As per world economic forum report about65\% students now entering into the primary education, will do the jobs which do completely not exist today. The jobs existing today like sports referee, tele callers, tax preparers do not exist in future, they will vanish. New types of jobs will be coming into existence.

The municipal authorities may use the social media as the resource for the feedback from the citizens about their living standards, can take corrective measures in case of sanitation, water supply etc. the recycling of solid waste may take many changes and reusable products will be made by municipalities.

The people, governments and other organization should acquire minimum basic knowledge for harnessing the full advantages offered by smart technologies which helps the digital physical integration. it is hoped that the economic and social equality and stability.

Prof Sam Turner stated that, the technology is an evolution. The revolution which makes in reducing costs, improving productivity, quality, performance by doing so, it improves the business. 4 IR has a power to reshape existing methods of manufacturing, consumption, transportation, delivery. Internet of things is just a face of 4IR, 4 IR can change the things by using Big Data analytics, AI artificial intelligence, robotics, virtual reality, block chain etc.

The abrupt and radical change in a field is called as revolution. The revolution in agriculture made the human civilization into existence. The fourth industrial revolution is building on the base of third industrial revolution, it's powered by new breakthroughs in digital realm in AI, new materials, bio engineering etc.

\section{INDUSTRIAL REVOLUTION 4 (IR4)}

\section{Introduction}

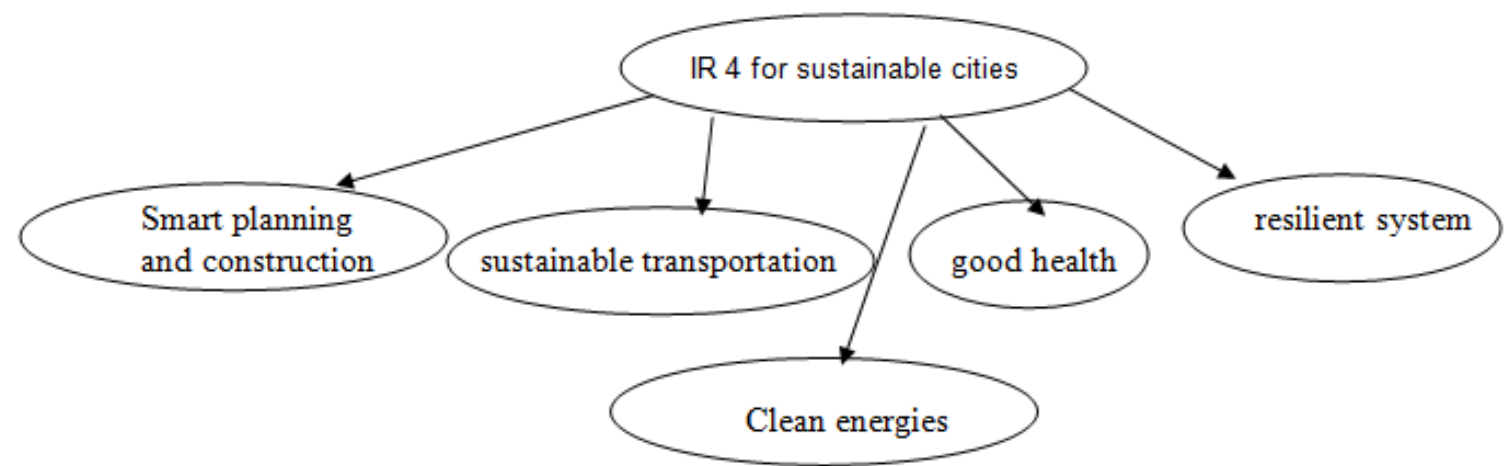

Figure 1: Technical Innovations for Sustainable Emerging Cities [16].

Earlier industrial revolutions 1IR, 2IR and 3 IR improved the production of goods and made profits. But the environment is polluted. Climate had changed to bad effects, pollution has increased to unsafe levels, sea water is filled 
with micro plastic wastages, loss of bio diversity, deforestation are the fruits of the earlier industrial revolutions. But the IR is intended to use green energies. 4IR intended to meet the environmental challenges.

As per an estimate, $2 / 3$ of world population will live in cities by 2020. This makes the cities and urban areas crowded with people. The sanitation, water supply, transportations can't be provided with existing technologies. IR 4 has to solve these problems.

The fourth IR is based on internet and green energies. Internet allows the fast flow of information and green energies protect the environment. The energies will be sold on a smart, continental interactive grid.

The IR4 makes the machines, automobiles remotely controlled. For examples the jet engines, military air planes, heavy earth moving vehicles, passenger and military automobiles will be remotely controlled and they are stopped at the borders of the countries.

Now days the spare parts of oil rigs are manufactured at the offshore with the 3D printers. With the IR 4, the sellers instead of selling a physical product, they may sell the soft copy of that product. The user has to print it with $3 \mathrm{D}$ at their place.

The patients can be cured remotely. The treatment will be done on the basis of exchanging information's between the patients and the medical institutes.

\section{Few Important Items used in 4IR}

- 3D Printer: It can be used to build assembly components, can print objects onsite, can be used to print solar roofs, intelligent package preparation for food products.

- Advanced Materials: Advanced materials have a great importance in 4IR, they can be used for making the following super insulation materials, advanced carbon fiber composites for lighter materials, solar spray PV building coatings, pollution absorbing materials, smart concrete reinforced structures.

- Robots: Robots are used for the following applications. Can work for construction of pre-fabricated builds, used to repair the faulty parts etc., can check and repair power transmission lines, can be used in waste collection in municipalities, can work in unmanned disaster rescue teams.

- Drones and Mini Air Vehicles: These can be used in many ways for surveillance, can deliver medicines in emergency, can monitor power supply and environment, and can participate in disaster management.

- Advanced Sensing Materials: These can be used to sense the dangerous explosive materials, drugs etc. Can be used in proactive and reactive security. They also can sense the health of humans and other living things. They can sense the environment effectively.

\section{Human Computer Interaction}

IR 4 has a great role to create interaction between human - machine, human - computer. Domestic robots will be used for helping humans in leading their daily life. They can be used for entertainment purpose, reminders of important things, used as digital interactive dairy. By recognizing the postures of humans the domestic robots will suggest the things to humans or will provide the necessary services. They can teach language to humans, they can translate a language to other language, they can read a text and say louder to humans, they write the text dictated by humans. People will make virtual islands with 
parks, swimming pools, buildings and people enjoy the virtual world. Many gadgets will come to existence to help human machine interaction.

The user interface is made of two parts, one is the interaction component which responses to the user while doing an activity, the other is software part which is concerned with the implementation of the interaction component.

Human computer interaction will be in three stages, first stage is to input command to computer, second stage relies on graphical user interphase and key board, third stage is that input is figured in smart phone. Virtual reality can be used in entertainment, education, military, aviation, medical science. Virtual human parts can be used in medical education.

\section{BENEFITS OF IR4}

There are innumerous benefits of 4th IR, few are mentioned below.

- Data sharing is the important feature of IR4. Data can be transferred across borders, individuals,

- IR 4 helps in smart planning and construction, sustainable transportation, clean energies, good health to people.

- Virtual products will be sent in markets to study the behavior of the customers. They can take feedback from customers and rebuild the product to launch real product.

- The result showed that entertainment, education and art take the lead, then is military and aviation, followed by medical science, then robots and commerce.

- Study of atmospheric weather can be much simpler and easy, sensors, drones are used to take feedback of atmosphere, and then computer software can give analytical results time to time.

- For disaster management instead of using humans, robots will be used. Sensors, cameras fitted to robots can interact with the surroundings and can take a decision to undertake a work.

- Robots assisted manufacture can improve productivity.

- The things will be done at an unimaginable faster rate.

\section{CONCLUSIONS}

The important feature of the IR 4 is that the human labor is replaced by machines or robots gradually. The robots and machines can interact to do the things. IR 4 is an amalgamation of many things like physical, digital and biological. Many new professions may come into existence like cyber-doctors, and they may design artificial human organs. The living conditions of the people will be improved. Their standards of living with interactive facilities will be provided by the municipalities. Water resources can be easily identified in the ground. The IR4 can be used to sense the climate change easily and help in disaster management. Ecosystem and bio diversity in the nature can be maintained.

\section{REFERENCES}

1. Sandeep, C.H., Naresh Kumar, S. \& Pramod Kumar, P. 2018, "Security challenges and issues of the IoT system", Indian Journal of Public Health Research and Development, Vol. 9, No. 11, pp. 748-753.

2. Seena Naik, K. \& Sudarshan, E. 2019, "Smart healthcare monitoring system using raspberry Pi on IoT platform", ARPN Journal of Engineering and Applied Sciences, Vol. 14, No. 4, pp. 872-876. 
3. Subba Rao, A. \& VidyaGarige, S. 2019, "IoT based smart energy meter billing monitoring and controlling the loads", International Journal of Innovative Technology and Exploring Engineering, Vol. 8, No.4S2, pp. 340-344.

4. Ramesh Babu, D., Koneru, S., Narasimha Rao, K.V., Satish Kumar, B., Kolati, S. \& Suman Kumar, N. 2019, "Identifying opportunities to start industries on the food production potential in Telangana and Andhra Pradesh, India", International Journal of Engineering and Advanced Technology, Vol. 8, No.5, pp. 2189-2193.

5. Kumar, K.S., Chythanya, K.R. \& Kumar, K.S. 2019, "A narrative improvement techniques used with the expert systems", International Journal of Innovative Technology and Exploring Engineering, vol. 8, no. 11, pp. 3269-3274.

6. Klaus Schwab “Will the Fourth Industrial Revolution have a human heart?” https:// www. weforum.org/agenda/2015/10/willthe-fourth-industrial-revolution-have-a-human-heart-and-soul

7. Megan Crouse "Bringing the Fourth Industrial Revolution to Life" https: //www.ecnmag. Com / news /2015/11/bringingfourth-industrial-revolution-life

8. Heather Stewart "Robot revolution: rise of 'thinking' machines could exacerbate inequality" https://www.theguardian.com/technology/2015/nov/05/robot-revolution-rise-machines-could-displace-third-of-uk-jobs

9. JaapBloem, Menno van Doorn, Sander Duivestein, David Excoffier, René Maas and Erik van Ommeren "The Fourth Industrial Revolution Things to Tighten the Link Between it and ot”, 2014 Sogeti VINT Production LINE UP boek en media bv, Groningen

10. İlker Güven Yilmaz, Doğuş Aygün, Zuhal Tanrikulu “Social Media's Perspective on Industry 4.0: A Twitter Analysis” scientific research publication Social Networking, 2017, 6, 251-261

11. Repelang Rabana "The impact of the $4^{\text {th }}$ industrial revolution of economic development - Devoloping a country agenda" Telkom consumer connectivity solutions,

12. Rushdiabdulrahim "Making sense of the 4th industrial revolution "Malaysian Foresight institute,

13. Adeboye, Albert Babajide. "Effects of Industrial Revolution on Ecclesiastical Architecture in Nigeria: A Case Study Of Faith Tabernacle At Ota." International Journal of Management, Information Technology and Engineering (BEST: IJMITE) 3.2 (2015): 27-34.

14. Trang, Ngothith. "The Fourth Industrial Revolution and Its Impact on the Field of Industrial Design." International Journal of Civil, Structural, Environmental and Infrastructure Engineering Research and Development (IJCSEIERD) 9.3 (2019):29-38.

15. Trivedi, Prachi, and Meghna Sharma. "Impact of Green Production and Green Technology on Sustainability: Cases on Companies in India." International Journal of Mechanical and Production Engineering Research and Development (IJMPERD) 7.6 (2017): 591-606.

16. Sarkar, Mihir Kanti, G M Faysal Ahmad, and M D Ayub Hossain. "Green Technologies in Wireless Networking: Major Issues." International Journal of Computer Science and Engineering (IJCSE) 2.2 (2013):85-92. 